\title{
ROLE OF SERUM LIPIDS IN GALLSTONE PATHOGENESIS: A CASE-CONTROL STUDY FROM PUNJAB
}

\author{
APINDER KAUR, AMANDEEP KAUR*, SATBIR KAUR \\ Department of Human Genetics, Punjabi University, Patiala - 147 002, Punjab, India. Email: amandeepkaur.arora899@gmail.com
}

Received: 30 September 2017, Revised and Accepted: 11 November 2017

ABSTRACT

Objective: Pathogenesis of gallstone (GS) disease is multifactorial, involving both genetic and environmental factors. The main pathogenic factor responsible for the hypersecretion of cholesterol into bile is the impaired lipid metabolism, which actually reflects the likelihood of GS formation. The study aims to determine the significance of serum lipids in the etiology of GS disease and to identify the possible confounding effects of age, gender, and body mass index (BMI) on GS disease.

Methods: A case-control study was conducted on 97 ultrasonically confirmed GS cases and 92 healthy controls which were further divided on the basis of gender, age group ( $\geq 40$ and $<40(y)$ ), BMI (obese and non-obese), and number of stones (single and multiple). The serum lipid parameters were estimated using the enzymatic kit assay. The statistical analysis of the lipid parameters in relation to age, gender, obesity, and stone number was done using the Student's t-test, Chi-square test, and Mann-Whitney U-test. $\mathrm{p}<0.05$ was considered statistically significant.

Results: The mean serum total cholesterol (TC) and low-density lipoprotein cholesterol (LDL-C) were significantly higher in cases as compared to controls ( $p=0.0001$ [95\% confidence interval [CI]: 33.3-61.2] and p=0.0001 [95\% CI: 36.6-64.2], respectively). The serum high-density lipoprotein cholesterol (HDL-C) level was non-significantly lower in GS patients as compared to controls ( $\mathrm{p}=0.4$ ). Obese female patients of age group $\geq 40$ (y) had an abnormal lipid profile with a significant rise in mean TC, LDL-C, and triglycerides (TG) (p<0.05) and were at higher risk of developing the GS disease as compared to controls. However, no probable effect of abnormal lipid profile, age, gender, and BMI on increasing the number of stones was found ( $\mathrm{p}>0.05)$.

Conclusion: Abnormal lipid parameters, especially high TC and LDL-C, were found to be significantly associated with GS disease. Increased age, obesity, and female gender along with dyslipidemia altogether elevate the risk of formation of GS. The formation of single/multiple stones was not influenced by the abnormal lipid profile, age, gender, and BMI.

Keywords: Gallstone disease, Serum lipids, Cholesterol, Total cholesterol, Low-density lipoprotein, High-density lipoprotein.

(C) 2018 The Authors. Published by Innovare Academic Sciences Pvt Ltd. This is an open access article under the CC BY license (http://creativecommons. org/licenses/by/4. 0/) DOI: http://dx.doi.org/10.22159/ajpcr.2018.v11i2.22846

\section{INTRODUCTION}

Gallstone (GS) disease is the most common gastrointestinal disorder constituting a major health burden [1,2]. It is more prevalent in the adult population (10-15\%) in developed countries with higher frequency among North American Indians and their admixtures (64.1\% in females and $29.5 \%$ in males) and lowest frequency among Africans $(<5 \%)[1,3,4]$. The prevalence of GS disease varies in different communities of India. The highest frequency rate of the disease has been reported in adult population (7.4\%) of North Indians [5]. The mortality rate of the disease is comparatively low in the developed countries $(0.6 \%)$ [4]. Multiple risk factors responsible for the GS formation include modifiable factors such as lifestyle factors (reduced physical activity, rapid weight loss, fasting, parity, and oral contraceptives [6,7]); dietary factors (high fat, high cholesterol, high refined carbohydrates, and low fiber [6]); metabolic syndrome (obesity, diabetes mellitus, dyslipidemia, and hyperinsulinemia [8-11]); and disease (Cirrhosis and Crohn's disease [4,12]). In contrast to this, non-modifiable factor includes family history, ethnicity, female sex, and increasing age $[6,13]$. Interaction between genetic factors, lipid metabolism, intestinal factors, and gallbladder hypomotility is important for the complete understanding of GS formation [2,14,15]. Among all the above mentioned risk factors, serum lipids are considered to be the most important risk factor involved in the pathogenesis of GS disease $[1,2,14]$. Lipids are the essential constituent of our body, which have the ability to maintain equilibrium and rule the cellular functions of our body. Hence, any abnormality in the lipid metabolism will lead to hypersecretion of hepatic cholesterol into bile in comparison to other lipids, which results in supersaturation of bile that further continues to grow and develop into solid cholesterol crystals $[6,16,17]$.

GS can be symptomatic and asymptomatic. About $80 \%$ of the GS cases are asymptomatic and only $20 \%$ develop symptoms to undergo cholecystectomy. Symptomatic GS is characterized by symptoms such as intense biliary pain in the upper abdomen that circulates through the back along with signs of nausea and vomiting [4]. Among the different types of stones, cholesterol GS is most common (80-90\%) and they exist as solitary or multiple different sizes and shapes $[18,19]$. Keeping in view a comparatively higher incidence of this disease in Northern India, the present study was aimed to investigate the relationship of serum lipid profile and the effect of potential factors such as age, gender, and obesity with the GS disease.

\section{METHODS}

\section{Study population}

A total of 97 cases, including 85 females and 12 males and 92 controls, including 86 females and 6 males, were considered. The study was carried at the Department of Human Genetics, Punjabi University, Patiala, between December 2014 and May 2015. The blood samples were collected from the Department of Surgery, Government Rajindra Hospital, Patiala. Ethical clearance for collecting the blood samples and other required information was taken from the Institutional Ethics Committee of Punjabi University, Patiala. Informed written consent was taken from all the patients after explaining them the objective of the study. Approximately $2 \mathrm{ml}$ of intravenous blood was taken from each 
participant after fasting period of $12 \mathrm{~h}$. Only ultrasonically confirmed cases of GS were taken and the patients undergoing treatment of gallbladder sludge, inflammation, polyps, and gallbladder carcinoma were excluded from the study. The duration of GS disease varies from months to (y) depending on the appearance of symptoms in patients. Surgery was only advised for patients who developed symptoms. Patients were not treated with any kind of medication before opting for surgery. Only the anti-inflammatory drugs and antibiotics were prescribed in case of cholecystitic patients. On the other side, the control group comprised randomly selected age-matched and sexmatched normal, healthy individuals from the same hospital with the ultrasonic exclusion of GS or any kind of metabolic disorder

\section{Biochemistry analysis}

The complete history, including demographic, clinical, and pathological of the GS patients, was recorded on the designed proforma. Body mass index $\left(B M I=\right.$ Weight $(\mathrm{kg}) /$ height $\left.(\mathrm{m})^{2}\right]$ of all the participants was calculated, and patients were categorized into obese and nonobese (normal and overweight) group according to the World Health Organization criterion $[16,20]$. Complete lipid profile, including TC, TG, HDL-C, LDL-C, was determined for both cases and controls by an enzymatic colorimetric method using ERBA Chem5X Biochemistry Analyzer. All the reagents were supplied by ERBA diagnostics Mannheim $\mathrm{GmbH}$, Germany. The desirable cutoff values for serum lipid levels were $<200 \mathrm{mg} / \mathrm{dl}$ for serum TC, $<150 \mathrm{mg} / \mathrm{dl}$ for TG, $>40 \mathrm{mg} / \mathrm{dl}$ for HDL, and $<100 \mathrm{mg} / \mathrm{dl}$ for LDL [16].

\section{Statistical analysis}

Statistical evaluation of the generated data was performed using the Statistical Package for the Social Sciences software version 16. The distribution of data was checked using histograms and normal curves. The variables having normal and non-normal distribution were represented in the form of mean \pm standard deviation and median \pm interquartile range (IQR), respectively. The quantitative variables were compared using Student's t-test and Mann-Whitney U-test, and qualitative variables were analyzed using the Chi-square test. ${ }^{*} \mathrm{p}<0.05$ was considered statistically significant.

\section{RESULTS}

In the present study, the majority of the individuals were females in comparison to males in both case and control group with the age ranging of 22-75 (y) in cases and 21-80 (y) in controls. The obesity was found to be $14 \%$ in cases and $13 \%$ in controls (Table 1).

The case-control comparison of the lipid profile was done to find out the association between dyslipidemia and GS disease (Table 2). The analysis revealed that the levels of serum TC and LDL-C were significantly higher in cases as compared to controls $(\mathrm{p}=0.0001$ [95\% confidence interval [CI]: 33.3-61.2] and $\mathrm{p}=0.0001$ [95\% CI: 36.6-64.2], respectively). The HDL-C level was observed to be lower in cases, but the difference was not statistically significant $(p=0.4)$. Further, the comparison of lipid profile on the basis of gender revealed that female patients have a significant increase in serum TC, LDL-C ( $p=0.0001)$, and TG levels $(p=0.002)$. No such significance was seen in males $(p>0.05)$.

Further, the females of diseased and nondiseased group were categorized into two age groups with age $\geq 40(y)$ and $<40(y)$ to analyze the effect of lipid profile on the GS disease in relation to age. The mean age of females of age group $\geq 40$ (y) was $53.17 \pm 10.3$ (y) in cases and $50.62 \pm 8.5(\mathrm{y})$ in controls, and the mean age of females of age group $<40(\mathrm{y})$ was $31.68 \pm 3.8(\mathrm{y})$ in cases and $29.8 \pm 5.2(\mathrm{y})$ in controls (Table 3 ). The two variables, TC and LDL-C, were found to have a significant rise in their level in the cases of age group $\geq 40(\mathrm{y})$ as compared to controls ( $p=0.0001$, CI: $34.7-72$ and CI: $37.8-74.52$ respectively at the $95 \%$ level). In the same age group, the serum HDL-C levels were found to be lower only in the cases, but not statistically significant $(\mathrm{p}=0.212)$. However, no such significance was seen in the age group of $<40(y)$ in both the groups.
Among the cases, $14(14.4 \%)$ were obese and 83 (85.5\%) were non-obese, and among controls, $12(13 \%)$ were obese and 80 (87\%) were non-obese when categorized on the basis of BMI. The casecontrol comparison of obese group was done to find out the relationship between obesity and dyslipidemia with GS disease (Table 4). A significant association was found with increase in serum TC and LDL-C levels only in the obese group of GS patients $(\mathrm{p}<0.05)$. The serum TG level was non-significantly higher $(\mathrm{p}=0.819)$ in GS patients as compared to controls. No such significance was found on comparison of the non-obese group of cases and controls

The comparison of categorical data (gender, obesity, and age group) and the lipid profile in relation to single and multiple stones is shown in Table 5. The complete data imply that the obesity ( $p=0.8$ [95\% CI: 0.36-3.57]), age ( $\mathrm{p}=0.9$ [95\% CI: 0.39-2.28]), and lipid profile ( $\mathrm{p}>0.05)$ had no significant effect on the stone number.

\section{DISCUSSION}

GS is the most common chronic gastrointestinal disorder and it involves many complications such as pancreatitis, cholecystitis, biliary tract obstruction and gallbladder cancer. Origin of the GS formation is considered to be multifactorial, which involves the complete interaction of environmental and genetic factors. It is considered to be one of the metabolic problems in which lipid abnormalities, diabetes, and obesity are found to be very common [4]. Dysfunctioning of lipid homeostasis also increases the risk of development of other diseases such as cardiovascular disease (CVD), atherosclerosis, and cirrhosis $[1,12,13,21,22]$.

The present findings justified the hypothesis of our study in which the case-control comparison of the serum lipid profile suggested that abnormal lipid levels, especially elevated TC and LDL-C were responsible for the formation of GS. There are many other case-control studies which clearly indicated the association between serum lipids and GS disease. One such earlier case-control study reported the positive association between the GS disease and the increased TG, LDL-C, and decreased HDL-C levels [23]. In an another study conducted by Dwivedi et al., the association of serum lipids with GS disease revealed the increased level of TC, LDL-C, TG, and VLDL-C and decreased level of HDL-C in GS patients as compared to controls [24]. Similarly, Naseem et al. did the quantitative analysis of serum lipids in GS patients and controls. They found elevated serum TC, LDL-C, and TG levels and diminished HDL-C levels in the study group in comparison of control group [20]. Contrary to our findings, Scragg et al. have reported the lower TC levels in cases as compared to controls in both the genders from which they revealed that increased concentration of TC was associated with decreased risk of GS disease [25].

Moreover, increased age has been considered as a responsible factor in the GS formation in many previous studies. Some investigators reported

Table 1: Distribution by age, gender, and BMI in case and control

\begin{tabular}{lll}
\hline Variables & Case (97) & Control (92) \\
\hline Age (y) & & \\
$\quad$ Mean \pm Sd & $44.16 \pm 13.5$ & $41 \pm 12.4$ \\
$\quad$ Range & $22-75$ & $21-80$ \\
Females & & \\
$\quad$ Mean \pm SD & $43.5 \pm 13.4$ & $41.2 \pm 12.6$ \\
$\quad$ Range & $22-75$ & $21-80$ \\
Males & & \\
$\quad$ Mean $\pm S D$ & $40.5 \pm 9.7$ & $38.1 \pm 9.2$ \\
$\quad$ Range & $25-50$ & $25-50$ \\
Gender & $85(88)$ & $86(93)$ \\
$\quad$ Females n (\%) & $12(12)$ & $6(6)$ \\
$\quad$ Males n (\%) & & \\
BMI & $14(14)$ & $80(87)$ \\
$\quad$ Obese n (\%) & $83(86)$ & \\
$\quad$ Non-obese n (\%) &
\end{tabular}


Table 2: Comparison of the serum lipids between cases and control

\begin{tabular}{|c|c|c|c|c|c|}
\hline \multirow[t]{2}{*}{ Serum lipid parameters $(\mathrm{mg} / \mathrm{dl})$} & \multicolumn{2}{|l|}{ Mean \pm SD } & \multirow{2}{*}{$\begin{array}{l}\text { p value } \\
\text { t-test }\end{array}$} & \multicolumn{2}{|l|}{$95 \% \mathrm{CI}$} \\
\hline & Case (97) & Control (97) & & Lower & Upper \\
\hline TC & $186.76 \pm 52.46$ & $139.45 \pm 44.43$ & 0.0001 & 33.32 & 61.29 \\
\hline HDL-C & $45.06 \pm 13.63$ & $47.36 \pm 23.91$ & 0.414 & -7.85 & 3.24 \\
\hline LDL-C & $116.41 \pm 50.66$ & $65.93 \pm 45.009$ & 0.0001 & 36.69 & 64.24 \\
\hline VLDL-C & $26.59 \pm 23.60$ & $26.30 \pm 16.75$ & 0.923 & -5.61 & 6.19 \\
\hline
\end{tabular}

SD: Standard deviation, CI: Confidence interval, TC: Total cholesterol, LDL-C: Low-density lipoprotein cholesterol, HDL-C: High-density lipoprotein cholesterol,

TG: Triglycerides. VLDL-C: Very low-density lipoprotein cholesterol. Boldfaced values indicate a significant difference

Table 3: Case-control comparison of the serum lipids according to age

\begin{tabular}{|c|c|c|c|c|c|c|}
\hline \multirow{2}{*}{$\begin{array}{l}\text { Serum lipid } \\
\text { parameters (mg/dl) }\end{array}$} & \multicolumn{2}{|l|}{ Mean \pm SD } & \multirow{2}{*}{$\begin{array}{l}p \text { value } \\
\text { t-test }\end{array}$} & \multicolumn{2}{|l|}{ Mean \pm SD } & \multirow{2}{*}{$\begin{array}{l}\text { p value } \\
\text { t-test }\end{array}$} \\
\hline & $\begin{array}{l}\text { Female case (47) } \\
(\text { age } \geq 40(y))\end{array}$ & $\begin{array}{l}\text { Female control (47) } \\
(\text { age } \geq 40(y))\end{array}$ & & $\begin{array}{l}\text { Female case (38) } \\
(\text { age }<40(y))\end{array}$ & $\begin{array}{l}\text { Female control (39) } \\
(\text { age }<40(y))\end{array}$ & \\
\hline $\mathrm{TC}$ & $189.44 \pm 50.74$ & $136.04 \pm 39.84$ & 0.0001 & $153.92 \pm 32.48$ & $139.81 \pm 50.53$ & 0.150 \\
\hline $\mathrm{TG}$ & $122.78 \pm 73.05$ & $118.17 \pm 72.18$ & 0.759 & $113.18 \pm 69.27$ & $140.68 \pm 96.49$ & 0.156 \\
\hline HDL-C & $45.97 \pm 12.68$ & $51.45 \pm 27.09$ & 0.212 & $44.11 \pm 14.16$ & $42.74 \pm 20.61$ & 0.736 \\
\hline LDL-C & $117.21 \pm 48.09$ & $61.25 \pm 42.38$ & 0.0001 & $97.65 \pm 45.09$ & $78.76 \pm 49.99$ & 0.086 \\
\hline VLDL-C & $27.77 \pm 23.98$ & $23.64 \pm 14.42$ & 0313 & $22.62 \pm 13.74$ & $28.29 \pm 19.33$ & 0.143 \\
\hline
\end{tabular}

SD: Standard deviation, TC: Total cholesterol, LDL-C: Low-density lipoprotein cholesterol, HDL-C: High-density lipoprotein cholesterol, TG: Triglycerides.

VLDL-C: Very low-density lipoprotein cholesterol. Boldfaced values indicate a significant difference.

Table 4: Case-control comparison of serum lipids according to BMI

\begin{tabular}{|c|c|c|c|c|c|}
\hline \multirow[t]{2}{*}{ Serum lipid parameters $(\mathrm{mg} / \mathrm{dl})$} & \multicolumn{2}{|l|}{ Mean \pm SD } & \multirow{2}{*}{$\begin{array}{l}\text { p value } \\
\text { t-test }\end{array}$} & \multicolumn{2}{|l|}{$95 \% \mathrm{CI}$} \\
\hline & Obese case (14) & Obese control (12) & & Lower & Upper \\
\hline $\mathrm{TC}$ & $226.93 \pm 53.19$ & $137.46 \pm 40.20$ & 0.0001 & 50.75 & 128.18 \\
\hline HDL-C & $47.23 \pm 12.92$ & $46.67 \pm 30.39$ & 0.950 & -17.84 & 18.96 \\
\hline LDL-C & $149.25 \pm 55.63$ & $61.34 \pm 45.74$ & 0.0001 & 46.22 & 129.58 \\
\hline VLDL-C & $30.44 \pm 12.91$ & $29.12 \pm 17.72$ & 0.829 & -11.11 & 13.74 \\
\hline
\end{tabular}

SD: Standard deviation, CI: Confidence interval, TC: Total cholesterol, LDL-C: Low-density lipoprotein cholesterol, HDL-C: High-density lipoprotein cholesterol,

TG: Triglycerides. VLDL-C: Very low-density lipoprotein cholesterol. Boldfaced values indicate a significant difference

Table 5: Formation of single/multiple stone in relation to gender, age group, BMI and serum lipids

\begin{tabular}{|c|c|c|c|c|}
\hline Characterstics & Single stone (39) & Multiple stone (58) & Total & $\mathrm{p}$ value \\
\hline \multicolumn{5}{|l|}{ Gender } \\
\hline Male (n, \%) & $6(50)$ & $6(50)$ & $12(12.3)$ & 0.46 \\
\hline Female (n, \%) & $33(39)$ & $52(61)$ & 85 (87.6) & Chi-square test \\
\hline \multicolumn{5}{|l|}{ Female } \\
\hline Age $\geq 40$ (y) (n, \%) & $18(38)$ & $29(62)$ & $47(55.2)$ & 0.9 \\
\hline Age $<40(y)(n, \%)$ & 15 (39) & $23(61)$ & $38(44.7)$ & Chi-square test \\
\hline \multicolumn{5}{|l|}{ BMI } \\
\hline Obese (n, \%) & $6(43)$ & $8(57)$ & $14(14.4)$ & 0.8 \\
\hline Non-obese $(n, \%)$ & $33(40)$ & $50(60)$ & $83(85.5)$ & Chi-square test \\
\hline \multicolumn{5}{|l|}{ TC } \\
\hline Median (IQR) & $183(88)$ & $183.5(61)$ & $183(80)$ & $\begin{array}{l}0.974 \\
\text { MW-U test }\end{array}$ \\
\hline \multicolumn{5}{|l|}{$\mathrm{TG}$} \\
\hline Median (IQR) & $106(65)$ & $110(115)$ & $106(79)$ & $\begin{array}{l}0.561 \\
\text { MW-U test }\end{array}$ \\
\hline \multicolumn{5}{|l|}{ HDL-C } \\
\hline Median (IQR) & $44(20)$ & $39.5(23)$ & $43(20)$ & $\begin{array}{l}0.189 \\
\text { MW-U test }\end{array}$ \\
\hline \multicolumn{5}{|l|}{ LDL-C } \\
\hline Median (IQR) & $116.9(67)$ & $118.3(58)$ & $118(65.8)$ & $\begin{array}{l}0.825 \\
\text { MW-U test }\end{array}$ \\
\hline \multicolumn{5}{|l|}{ VLDL-C } \\
\hline Median (IQR) & $21.2(14)$ & $22(23)$ & $21.26(21.2)$ & $\begin{array}{l}0.471 \\
\text { MW-U test }\end{array}$ \\
\hline
\end{tabular}

MW-U test: Mann-Whitney U test, BMI: Body mass index, IQR: Interquartile range, TC: Total cholesterol, LDL-C: Low-density lipoprotein cholesterol,

HDL-C: High-density lipoprotein cholesterol, TG: Triglycerides. VLDL-C: Very low-density lipoprotein cholesterol 
that the possibility of GS disease in female increases with age ( $\geq 40 \mathrm{y})$ as compared to males with the rise in its symptoms and complications such as abnormal lipid profile $[4,20,26]$. In the present study, the case-control comparison of the females of $\geq 40 y^{\prime}$ age group revealed high serum TC and LDL-C and reduced HDL-C in the diseased group. Although the results of the serum lipids are non-significant in female patients of age group $<40 \mathrm{y}$, they indicate that the females of this age group have more chances to develop lipid profile abnormalities in the future. Female hormones, especially the level of estrogens are the clear basis of those whose levels are increased during pregnancy (results in the development of up to $30 \%$ biliary sludge) or hormone therapy or use of oral contraceptives which in turn raise the levels of cholesterol in bile and reduction in gallbladder movement leading to the formation of GS. The risk further increases in post-menopausal women on estrogenreplacement therapies. Finding similar to the current study has been observed in the study conducted by Batazoo et al. in which the serum TC, LDL-C, and TG levels were higher in female patients of age group $\geq 40 \mathrm{y}$ in comparison to controls. Of these parameters, only LDL-C level was found to be statistically significant [1]. Similarly, Naseem $e t$ al. also showed the positive association of elevated serum TC, LDL-C and TG levels and diminished HDL-C levels in the female GS patients of age group $\geq 40 \mathrm{y}[20]$. Some investigators found the association only between GS disease and decreased HDL levels in the senior citizens of Taiwan [27]. This illustrates that aging is a confounding factor for altered lipid profile and leads to the formation of GS.

Metabolic factor such as obesity is also a contributing factor for the formation of GS disease. Abnormal lipid profile along with obesity had shown a combinatorial effect on increasing probability of causing a GS disease. Some studies have reported that in obese individuals, the activity of hydroxyl-3-methylglutaryl-CoA reductase was increased that was considered as a rate-limiting step for cholesterol synthesis. This augments its secretion into bile and consequently escalated cholesterol GS formation [26]. The results of the current study showed a significant rise in the level of TC and LDL-C only in the obese female patients, which signifies that obese females are at higher risk of developing stones as compared to non-obese females. Similarly, Corrina et al. also showed the strongest association between obesity and GS disease which was found to be much stronger in females as compared to males. They also reported that at younger age, overweight individuals have 2 -fold elevated risk of GS disease, whereas moderately and highly obese individuals have 4-6-fold elevated risk of the disease [26]. Another study conducted by Eun et al. showed the association between GS and dyslipidemia with increased TG and diminished HDL-C levels in obese female patients. They found that these abnormalities were associated with increased cholesterol supersaturation and hence greater risk for the formation of cholesterol stones [28]. Abnormal serum lipid levels, especially decreased HDL-C and elevated TC, TG and LDL-C, were also found to be involved in the etiology of other diseases in association with obesity. In a study conducted by Nasser et al., the overweight and obese children were at increased risk of hypertriglyceridemia as compared to those children who were not overweight or obese [29]. Considering the major role of dyslipidemia in coronary artery disease, it is essential to evaluate the patterns of lipid profile carefully in the GS patients who are at higher risk of developing CVD in the future.

Some studies have reported the association between GS disease and increasing number of stones in relation to lipid profile, age, gender, and obesity [2]. In our study, the majority of the stones were multiple $(60 \%)$. The present results revealed that age and obesity had no effect on the number of stones. The effect of gender difference on stone number was not certain due to lesser number of males in our study. Furthermore, the quantitative analysis of lipid profile revealed that there is no association between altered lipid metabolism and increasing number of stones. Domeyer et al. conducted a study to investigate the correlation of gallbladder inflammation with the number and the size of the stones. Their results revealed that older patients have smallsized higher number of stones. They also reported that the severity of gallbladder inflammation aggravated at a younger age with the single stone [30]. Another prospective study by Csendes et al. had been done among the female patients to investigate the association of the number and size of the stone with the gallbladder carcinoma. They found that aging is the only predictor for multiple and large-sized stones among gallbladder cancer patients [31]. Similar to our findings, Sebahattin et al. also investigated the relationship between lipid profile, age, gender, and number of stones. A weak correlation was found only between TC and stone number, but age and gender had no effect on the increase in the number of stones [2]. Thus, we believe that the presence of a number of stones in an individual is completely independent (in our patients) and more likely a matter of chance.

\section{CONCLUSION}

The present study concludes that the serum lipids, especially serum TC and LDL-C, were significantly higher in obese female patients of age group $\geq 40 \mathrm{y}$. Thus, increased age in female with the rising epidemic of obesity along with other metabolic syndrome is certain to elevate the frequency and complexity of GS formation. Hence, it is important to screen those patients having GS with impaired lipid homeostasis which imposes a higher risk and warning signs for CVD in the future.

\section{ACKNOWLEDGMENT}

The authors are thankful to the University Grants Commission for providing fellowship under the Basic Scientific Research fellowship scheme (No. 6979, 6967). The authors are also thankful to the Head, Department of Human Genetics, Punjabi University, Patiala, for her valuable guidance and support.

\section{REFERENCES}

1. Batajoo H, Hazra NK. Analysis of serum lipid profile in cholelithiasis patients. J Nepal Health Res Counc 2013;11:53-5.

2. Celika S, Doganb S, Arslanc H. Is the presence of single or multiple gallstones a matter of chance? What is the relationship between the number of stones and lipid profile, age, gender, and stone type? J Univ Surg 2015;3:13

3. Friedman GD. Natural history of asymptomatic and symptomatic gallstones. Am J Surg 1993;165:399-404.

4. Stinton LM, Shaffer EA. Epidemiology of gallbladder disease: Cholelithiasis and cancer. Gut Liver 2012;6:172-87.

5. Sachdeva S, Khan Z, Ansari MA, Khalique N, Anees A. Lifestyle and gallstone disease: Scope for primary prevention. Indian J Community Med 2011;36:263-7.

6. Di Ciaula A, Wang DQ, Bonfrate L, Portincasa P. Current views on genetics and epigenetics of cholesterol gallstone disease. Cholesterol 2013;2013:298421.

7. Heaton KW, Braddon FE, Mountford RA, Hughes AO, Emmett PM. Symptomatic and silent gall stones in the community. Gut 1991;32:316-20.

8. Méndez-Sánchez N, Chavez-Tapia NC, Motola-Kuba D, Sanchez-Lara K, Ponciano-Rodríguez G, Baptista H, et al. Metabolic syndrome as a risk factor for gallstone disease. World J Gastroenterol 2005;11:1653-7.

9. Ata N, Kucukazman M, Yavuz B, Bulus H, Dal K, Ertugrul DT, et al. The metabolic syndrome is associated with complicated gallstone disease. Can J Gastroenterol 2011;25:274-6.

10. Shaffer EA. Epidemiology and risk factors for gallstone disease: Has the paradigm changed in the $21^{\text {st }}$ century? Curr Gastroenterol Rep 2005;7:132-40.

11. Cuevas A, Miquel JF, Reyes MS, Zanlungo S, Nervi F. Diet as a risk factor for cholesterol gallstone disease. J Am Coll Nutr 2004;23:187-96.

12. Ghadir MR, Riahin AA, Havaspour A, Nooranipour M, Habibinejad AA. The relationship between lipid profile and severity of liver damage in cirrhotic patients. Hepat Mon 2010;10:285-8.

13. Coelho VG, Caetano LF, Liberatore Júnior Rdel R, Cordeiro JA, Souza DR. Lipid profile and risk factors for cardiovascular diseases in medicine students. Arq Bras Cardiol 2005;85:57-62.

14. Lambou-Gianoukos S, Heller SJ. Lithogenesis and bile metabolism. Surg Clin North Am 2008;88:1175-94, vii.

15. Van Erpecum KJ. Pathogenesis of cholesterol and pigment gallstones: An update. Clin Res Hepatol Gastroenterol 2011;35:281-7.

16. Weerakoon HT, Ranasinghe S, Navaratne A, Sivakanesan R, Galketiya KB, Rosairo S. Serum lipid concentrations in patients with 
cholesterol and pigment gallstones. BMC Res Notes 2014;7:548.

17. Abdullah UY, Jassim HM, Baig AA, Khorsheed RM, Al-Khayat AH, Sulong AF, et al. Gallstones in patients with inherited hemolytic diseases. Int J Pharm Pharm Sci 2015;7:9-15.

18. Portincasa P, Moschetta A, Palasciano G. Cholesterol gallstone disease. Lancet 2006;368:230-9.

19. Sama C, Labate AM, Taroni F, Barbara L. Epidemiology and natural history of gallstone disease. Semin Liver Dis 1990;10:149-58.

20. Channa NA, Khand F, Ghanghro AB, Soomro AM. Quantitative analysis of serum lipid profile in gallstone patients and controls. Pak J Anal Environ Chem 2010;11:59-65.

21. Lin IC, Yang YW, Wu MF, Yeh YH, Liou JC, Lin YL, et al. The association of metabolic syndrome and its factors with gallstone disease. BMC Fam Pract 2014;15:138.

22. Gururaja GM, Mundkinajeddu D, Kumar SA, Allan JJ, Dethe SM, Agarwal A. Cholesterol lowering potentials of a blend of standardized methanol extracts of Moringa oleifera leaves and fruits in Albino Wistar rats. Int J Pharm Pharm Sci 2016;8:262-8.

23. Chapman BA, Wilson IR, Frampton CM, Chisholm RJ, Stewart NR, Eagar GM, et al. Prevalence of gallbladder disease in diabetes mellitus. Dig Dis Sci 1996;41:2222-8.

24. Dwivedi S, Singh S, Singh D, Tiwari S. Association of non clinical characteristics and lipid profile with gall bladder stone patients; a case control study. Panacea J Med Sci 2014;4:62-4.
25. Scragg RK, Calvert GD, Oliver JR. Plasma lipids and insulin in gall stone disease: A case-control study. Br Med J (Clin Res Ed) 1984;289:521-5

26. Koebnick C, Smith N, Black MH, Porter AH, Richie BA, Hudson S. Pediatric obesity and gallstone disease: Results from a crosssectional study of over 510,000 youth. J Pediatr Gastroenterol Nutr 2012;55:328-33

27. Chen CY, Lu CL, Lee PC, Wang SS, Chang FY, Lee SD. The risk factors for gall stone disease among senior citizens: An oriental study. Hepato Gastroenterol 1999;46:1067-612.

28. Yoo EH, Lee SY. The prevalence and risk factors for gallstone disease. Clin Chem Lab Med 2009;47:795-807.

29. Rizk NM, Yousef M. Association of lipid profile and waist circumference as cardiovascular risk factors for overweight and obesity among school children in Qatar. Diabetes Metab Syndr Obes 2012;5:425-32

30. Domeyer PJ, Sergentanis TN, Zagouri F, Tzilalis B, Mouzakioti E, Parasi A. Chronic cholecystitis in elderly patients. Correlation of the severity of inflammation with the number and size of the stones. In Vivo 2008;28:269-72.

31. Csendes A, Becerra M, Rojas J, Medina E. Number and size of stones in patients with asymptomatic and symptomatic gallstones and gallbladder carcinoma: A prospective study of 592 cases. J Gastrointest Surg 2000;4:481-5. 